Document downloaded from:

http://hdl.handle.net/10251/64397

This paper must be cited as:

Serrano Jareño, MA.; Bosca Berga, JV. (2011). Validation of a method to estimate direct normal irradiance of UVA and PAR bands from global horizontal measurements for cloudless sky conditions in Valencia, Spain, by a measurement campaign. Theoretical and Applied Climatology. 103(1):95-101. doi:10.1007/s00704-010-0284-9.

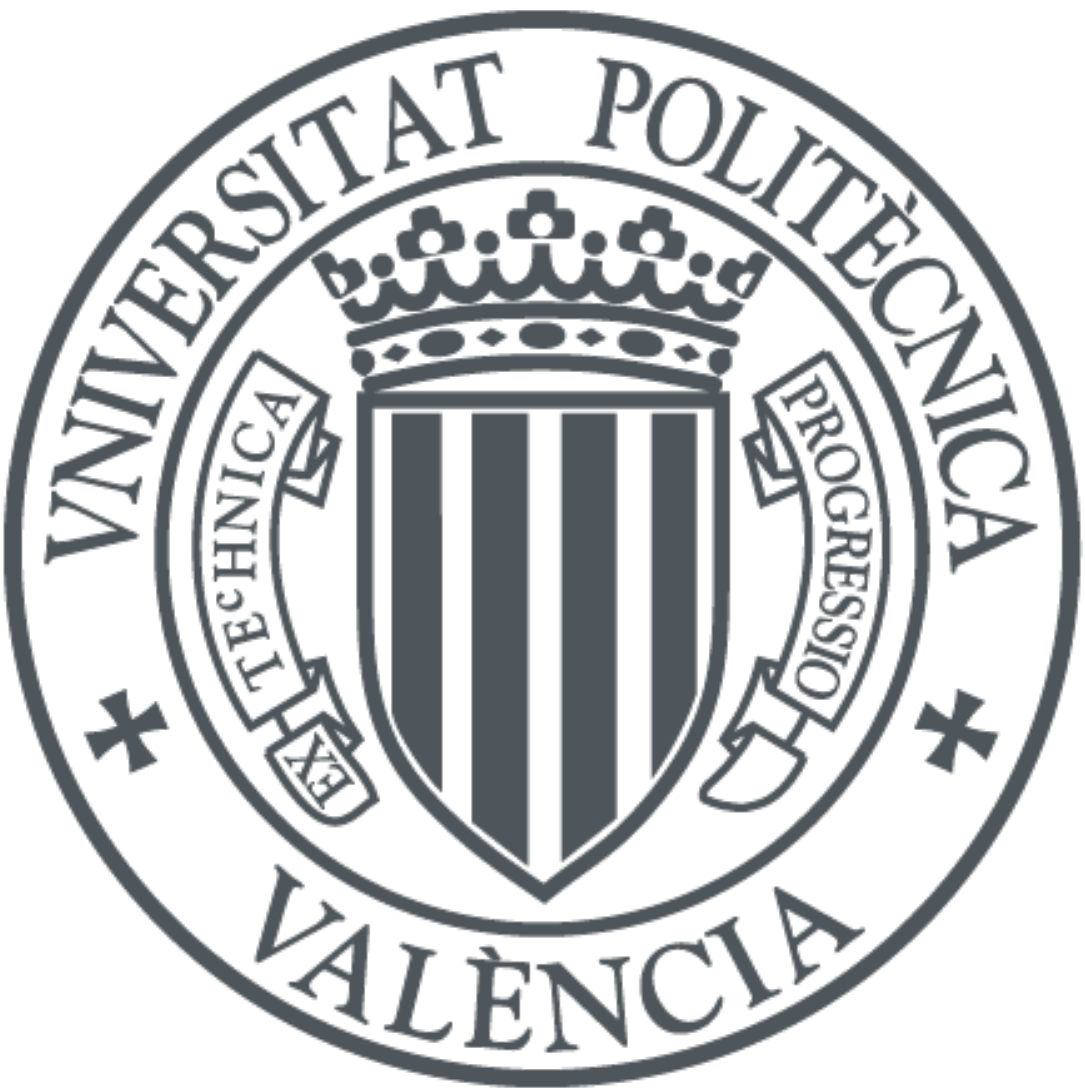

The final publication is available at

http://dx.doi.org/10.1007/s00704-010-0284-9

Copyright Springer Verlag (Germany)

Additional Information 


\title{
Validation of a Method to Estimate Direct Normal Irradiance of UVA and PAR Bands from Global Horizontal Measurements for Cloudless \\ Sky Conditions in Valencia, Spain, by a Measurement Campaign
}

María-Antonia Serrano, J. V. Boscà

\begin{abstract}
A method is proposed to provide measurement of direct normal solar irradiance of bands with wavelength ranges $(280-315 \mathrm{~nm}),(315-400 \mathrm{~nm}),(400-700 \mathrm{~nm})$, and $(290-385 \mathrm{~nm})$ from measurements of global horizontal band irradiance in Mediterranean cities with a mean-rural-urban atmosphere and a similar latitude to that of Valencia.

Global and normal direct irradiance data for every air mass were obtained by applying the SMART2 model to the atmosphere of Valencia. The direct normal to global irradiance ratio was parameterised versus the relative optical air mass.

A measurement campaign of global horizontal and diffuse irradiance of UVA and PAR bands was carried out in Valencia, after which, the inferred direct normal irradiance was compared with those provided by the method. The result of the comparison shows that the method is acceptably accurate.

The proposed model tends to underestimate the direct normal irradiance of the UVA band by $6 \%$, although for values below $25 \mathrm{~W} / \mathrm{m}^{2}$ the model overestimates the direct irradiance by $6 \%$, while for values above $25 \mathrm{~W} / \mathrm{m}^{2}$ the model underestimates it by $10 \%$. The other two error estimators used ranging from 11 to $15 \%$ are similar in the defined interval measurements in relation to the whole UVA band.

Regarding the PAR band, the model overestimates the direct normal irradiance of the PAR band by only $2.2 \%$. With this, the results of the PAR band are more conclusive, as it has been found that for direct normal irradiance values higher than $280 \mathrm{~W} / \mathrm{m}^{2}$ the $\mathrm{MBE}$ error is almost zero and the other two estimator errors are small, about $5 \%$.
\end{abstract}

Keywords: Direct Normal irradiance; Estimation model; Ultraviolet solar irradiance; Photosynthetically Active Radiation.

\section{Introduction}

Radiation of bands of the solar spectrum are measured and analysed for different reasons. UVA Bands in the 315-400 $\mathrm{nm}$ range, and PAR (Photo synthetically Active Radiation) in the 400-700 nm range,

María-Antonia Serrano ( ), José V. Boscà

Department of Applied Physics,

Universidad Politécnica de Valencia, Camino de Vera s/n 46022 Valencia, Spain

*Corresponding author: Tel: +34-963877007; Fax: +34-963879896,

e-mail: mserranj@fis.upv.es . 
according to the standard nomenclature of the Commission Internationelle de l'Eclairage, CIE (Barth et al. 1999), have a particular interest due to their influence on animal and plant life.

A $T_{B}$ factor was defined (Serrano et al. 2008), in a similar way as it was for broadband irradiance with the establishment of Linke's Factor, as the ratio of the current optical depth, for a given band, to the optical depth of a CDA (clean and dry atmosphere). $\mathrm{T}_{\mathrm{B}}$ can be useful to establish a band clearness index independent from the zenith angle. But to determine this factor direct normal irradiance $\left(\mathrm{I}_{\mathrm{n}}\right)$ of the band must be known.

In the cited reference a method was developed to provide $I_{n}$ of two bands of wavelength ranges 280-315 $\mathrm{nm}$ and 290-385 nm, with the available measurements of global horizontal irradiance (I) of these bands as input, with the objective of determining values of the $T_{B}$ factor of these bands in Valencia, Spain.

In this paper the Estimation Method, hereinafter to be referred to as EM, has been improved and applied to obtain parameterizations for the aforementioned UVA and PAR bands in order to determine direct normal irradiance data. Eventually a measurement campaign was accomplished to validate EM for Valencia, in cloudless sky conditions, by a comparison of the values produced using EM with the direct normal irradiance obtained by the measurement campaign.

In Section 2 we describe the improvements applied to EM, and we show how the two new $\mathrm{I}_{\mathrm{n}} / \mathrm{I}$ parameterizations versus the relative optical air mass $\left(\mathrm{m}_{\mathrm{r}}\right)$ for UVA and PAR were obtained. The relevant equations are shown in Table 1 and subsequent graphical representations in Figures 1 and 2 of this section.

Section 3 describes the measurement campaign of global horizontal and diffuse irradiance of the bands, carried out at the Polytechnic University of Valencia in order to validate EM. The experimental direct normal irradiance of the bands was inferred from global horizontal and diffuse measurements. In this section the instrumentation and the campaign procedures are described, and there is also a discussion on the best method of correcting the shadow band used to measure the diffuse irradiance.

Section 4 contains the results of the comparison and a discussion of the errors, and it is shown that EM is acceptably accurate. In this section inaccuracies are analysed and the intervals in which underestimation or overestimation was produced are also observed. Eventually the mean bias error of the estimation of direct normal irradiance for the UVA band is $6 \%$, and for the PAR band it is $2.2 \%$.

\section{The Estimation Method}

Through the EM, parameterizations for UVA and PAR bands were found so that, if an experimental measurement of global horizontal irradiance is available, then direct normal irradiance can be inferred by means of the parameterization.

To obtain the parameterizations, global and direct normal irradiance data for different values of air mass were obtained by applying the SMART2 model, Gueymard (1995), to the atmosphere of Valencia, and then the ratio of direct normal to global horizontal irradiances was parameterized versus the relative optical air mass.

The version of the model was Smarts 2.9.2 Model, Gueymard (2003), as summarized in Serrano et al. (2008). In this paper another value for the Angström $\beta$ coefficient was searched to meet the mean 
turbidity of the atmosphere of Valencia.

A new $\beta$ average value was established, from the determination of the Angström turbidity coefficient along the period from 1996 to 2004. Measurements of broadband global horizontal and diffuse irradiance were available for the whole of this period, and beta values throughout the period were determined using Pinazo's method, Pinazo et al. (1995). Average monthly values were then obtained for the whole period as shown in Table 1 . The average monthly value of $\beta=0.081$ was taken as input for the model.

Table 1 Mean values of the Ångström turbidity coefficient for the period 1996-2004

\begin{tabular}{llllllllllllll}
\hline Month & Jan & Feb & Mar & Apr & May & Jun & Jul & Aug & Sep & Oct & Nov & Dec & Average \\
\hline $\boldsymbol{\beta}$ & 0.058 & 0.061 & 0.079 & 0.072 & 0.089 & 0.104 & 0.103 & 0.096 & 0.102 & 0.081 & 0.075 & 0.059 & 0.081 \\
\hline
\end{tabular}

The rest of the options chosen for application of the Smarts 2 program are summarized in Serrano et al. (2008), and were selected bearing in mind the geographical coordinates and the climatic characteristics of the city of Valencia, of latitude $39.48^{\circ} \mathrm{N}$, corresponding to an average atmosphere between Mild Latitude Summer (MLS), and Mild Latitude Winter (MLW) at a latitude of $45^{\circ} \mathrm{N}$. Also the spectral absorption coefficients of water vapour, ozone, $\mathrm{NO}_{2}$ and uniformly mixed gases were the same. The same values were applied in this paper for the carbon dioxide concentration adopted and the effective pathlength for the atmospheric constituents for the average atmosphere including that of $\mathrm{O}_{3}$. Among the seven extraterrestrial solar spectrums existing in the model the choice was that of Gueymard (2003).

Smarts2 model considers nine aerosol models available, then the Standard Radiation Atmosphere was chosen, and the corresponding type was urban-industrial such as that applied by Utrillas et al. (1998) for Valencia. The parameters corresponding to the coefficient of exponent $\alpha$ of Ångström for this aerosol model are also summarized in Serrano et al. (2008).

Eventually the UVA and PAR bands were parameterized. The global horizontal and direct normal irradiance of each band were generated applying Gueymard's SMART 2.9.2 model (2003) for values of air masses from 1.05 up to 6 for the UVA and 12 for the PAR band, since for air masses above these values global irradiance is near to zero.

The increase of $\mathrm{m}_{\mathrm{r}}$ was $\Delta \mathrm{m}_{\mathrm{r}}=0.05$ when $\mathrm{m}_{\mathrm{r}}<2, \Delta \mathrm{m}_{\mathrm{r}}=0.1$ when $2<\mathrm{m}_{\mathrm{r}}<6$, and $\Delta \mathrm{m}_{\mathrm{r}}=0.5$ for $\mathrm{m}_{\mathrm{r}}>6$.

The ratio of direct normal to global horizontal irradiance for every band was parameterized in accordance with their respective air mass values.

Figures 1 and 2 show the graphic representations for parameterization of UVA and PAR bands. The parameterized functions for every band of the correlation of $I_{n} / I$ versus $m_{r}$ and their $R^{2}$ coefficients are shown in Table 2, where $I_{n}$ is the direct normal band irradiance and $I$ is the global horizontal band irradiance, both provided by the Smarts 2 model. 


\begin{tabular}{ccc}
\hline Band & $\mathbf{I} / \mathbf{I}$ & $\mathbf{R}^{2}$ \\
\hline UVA & $4.708 \mathrm{E}-2+0.8596 \mathrm{~m}_{\mathrm{r}}-0.3504 \mathrm{~m}_{\mathrm{r}}{ }^{2}+5.097 \mathrm{E}-2 \mathrm{~m}_{\mathrm{r}}{ }^{3}-2.612 \mathrm{E}-3 \mathrm{~m}_{\mathrm{r}}{ }^{4}$ & 0.999 \\
PAR & $8.186 \mathrm{E}-2+0.8433 \mathrm{~m}_{\mathrm{r}}-9.592 \mathrm{E}-2 \mathrm{~m}_{\mathrm{r}}{ }^{2}+3.114 \mathrm{E}-3 \mathrm{~m}_{\mathrm{r}}{ }^{3}$ & 0.999 \\
\hline
\end{tabular}

Application of these parameterizations will determine direct normal irradiance of the band from experimental measurements of global horizontal irradiance for every $\mathrm{m}_{\mathrm{r}}$.

\section{Measurement campaign: Instrumentation}

\subsection{Instrumentation}

The station is located on the roof of the School of Design Engineering of the Polytechnic University of Valencia with coordinates of $0^{\circ} 20^{\prime} 18^{\prime \prime} \mathrm{W}, 39^{\circ} 28^{\prime} 49^{\prime \prime} \mathrm{N}$ which is $15 \mathrm{~m}$ above sea level, and hereinafter will be referred as ETSID Station. It is in the north of the city of Valencia, far from industrial areas and near a rural zone. The instruments are on horizontal platforms open to the sky without obstruction or shadows, except when expressly arranged for this purpose. It is equipped with an ELDONET (European Light DOsimeter NETwork) which measures solar irradiance in the spectral bands that include the wavelength intervals of 280-315 nm, 315-400 nm and 400-700 nm.

ELDONET is provided with a $10 \mathrm{MHz}$ microprocessor for shutter control, data acquisition and internal temperature control. It also has 3 preamplifiers for the respective channels, offset amplifiers, connections $(1 \mathrm{x}, 10 \mathrm{x}, 100 \mathrm{x})$, an external feeding source A/D and an RS 232 interface. The casing is moisture-proof and has reflecting sides for heat protection. The upper surface has a 2 " quartz dome. There are three filters for measuring UVB, UVA and PAR and photodiodes with a $10 \mathrm{~cm}$ Ulbricht integration sphere with a barium sulphate filling, besides external and internal temperature sensors.

The resolution and detection limit of this instrument is under $0.1 \mathrm{~W} / \mathrm{m}^{2}$ for PAR, $0.01 \mathrm{~W} / \mathrm{m}^{2}$ for UVA and $0.0005 \mathrm{~W} / \mathrm{m}^{2}$ for UVB. Under field conditions, the deviation from integrated values measured by calibrated spectroradiometers is lower than $10 \%$ for UVB, $5 \%$ for UVA and $2 \%$ for PAR. Reproductive capacity was from $1.4 \pm 1.0 \%$ for the PAR channel $1.9 \pm 1.5 \%$ for the UVA and $3.8 \pm 3.8 \%$ for the UVB channel as described in Häder et al. (1999). The software of the Data Adquisition System, DAS, takes and stores the measurements every minute and records one file per day.

The instrument was designed to establish the solar radiation European Light Dosimeter Network, which was coordinated and financed by the European Union, Häder et al. (1999). The ELDONET network includes 31 stations located all over Europe from the north of Sweden to the Canary Islands. 
The instrument was calibrated in July 2005 for the response cosine, and for the absolute irradiance of three channels according to the protocols followed by the European ELDONET project as described in Häder et al. (2001).

\subsection{Measurement campaign}

With the purpose of checking EM, a measurement campaign of diffuse irradiance of the bands was carried out with the same instruments that systematically measure global horizontal band irradiance. This campaign was carried out in June and July, 2006, at the ETSID Station, which automatically registers global horizontal irradiance of the bands by means of the DAS. In order to use the system to register diffuse irradiance measurements, the instrument was covered with a black shadow disk at several instants during the day.

To shade the instrument, the black shadow disk, with a $15 \mathrm{~cm}$ diameter, intercepted the sun's rays at a distance of $44 \mathrm{~cm}$, and for a duration of 4 minutes. This allowed the DAS to store at least three measurements each time, whose average value was taken as the diffuse horizontal irradiance, once it had been corrected as explained below due to the overshadowing of the shadow disk. The global horizontal irradiance was obtained from the average of the two contiguous measurements at the same instant, and then direct normal irradiance of the band was deduced from diffuse and global.

This operation was carried out every hour, of True Solar Time, between 8:00 h and 13:00 h, and the observer took note of the exact time when the database stored the modified measurements, and other atmospheric characteristics at that instant, such as visibility and cloudiness.

Table 3 Measurement data for global and diffuse irradiance of the UV and PAR bands and number of measurements per day.

\begin{tabular}{lll}
\hline Month & Days with measurements & Respective number of measurements/day \\
\hline June & $8,13,14,16,19-24,26,28-30$ & $2,5,1,1,3,2,4,6,5,2,6,5,5,6$ \\
July & $5,6,10,11,13,14,17-21,24,26,28,31$ & $5,6,6,2,6,4,6,4,5,7,6,4,7,6,6$ \\
Total number & 31 & 133 \\
\hline
\end{tabular}

The measurement campaign database, containing fewer cloudy periods than clear ones, consists of 31 effective days with 162 total measurements. Measurements of global and diffuse horizontal irradiance of the bands studied for this work were obtained. Direct normal irradiance was also calculated and information on cloud cover was also recorded for each period.

Measurements of totally and partially cloudy days were excluded from the database as per the criterion of the observer, resulting in a total of 133 available measurements for the UVA and PAR bands as shown in Table 3. Sometimes the presence of very thin clouds, or cirrus, made so little attenuation of solar radiation that they were also considered to be cloudless sky conditions. 


\subsubsection{Correction of shadow disk diffuse measurements}

The use of the shadow disk makes it necessary to correct the diffuse measurement, since this procedure not only eliminates direct normal irradiance but also part of the diffuse irradiance. To correct the effect of the disk on the diffuse irradiance data, we considered the model by Battles et al. (1995), based on Le Baron et al. (1990), which uses four parameters that take into account both the isotropic and anisotropic conditions to determine the correction factor. This model is recommended by Kudish et al. (2008) and Utrillas et al. (2007). Battles et al. (1995) performed a multiple linear regression analysis based on the four LeBaron et al. (1990) parameters. Their correction factor model consists of four equations, which are functions of three of the LeBaron parameters and the Drummond (1956) correction factor.

\subsubsection{Battles' model}

This model uses a correction factor for diffuse irradiance obtained from a multiple linear regression analysis from the parameters of the Le Baron model.

$$
C_{B}=1.245 \cdot C_{D}+0.522 \cdot \log \Delta+0.230 \cdot \log \varepsilon+0.322 \cdot e^{-1 / \cos \theta}
$$

based on the work by Perez et al. (1990). The four parameters are: geometric correction factor (the Drummond correction factor, $\mathrm{C}_{\mathrm{D}}$ ), solar zenith angle, $\theta_{\mathrm{z}}$, epsilon, $\varepsilon$, and delta, $\Delta$. The two latter parameters are indexes of the sky's clearness (a function of cloud conditions) and brightness (a function of cloud thickness or aerosol loading) respectively. The three parameters, $\theta, \varepsilon$ and $\Delta$ are used to describe the anisotropic contribution to the overall shadow ring correction factor. Epsilon and Delta were defined by Perez et al. (1990) in the following manner:

$$
\begin{aligned}
& \varepsilon=\left(I_{n, b, u}+I_{d}\right) / I_{d} \\
& \Delta=\frac{I_{d}}{I_{0} \cos \theta}
\end{aligned}
$$

where $I_{0}$ is the extraterrestrial irradiance obtained from Gueymard (2004), $I_{d}$ the horizontal diffuse irradiance, and $\mathrm{I}_{\mathrm{nbu}}$ the uncorrected normal incidence beam irradiance defined as

$$
I_{n, b, u}=\left(I_{g}-I_{d}\right) / \cos \theta
$$

The parameter coefficients $\varepsilon$ and $\Delta$ are obtained for total irradiance. In order to apply them to the range of the irradiance bands it was necessary to recalculate the intervals of the $\Delta$ and $\varepsilon$ parameters for a much smaller order of magnitude, as in Marín (2007) for the UVB band. An average value of the parameters $\varepsilon$ and $\Delta$ was obtained for the experimental parameters, for each of the bands shown in Tables 4 and 5 , which must satisfy: 
$0.522 \log \Delta=\operatorname{coef}_{\text {band }} \log \Delta_{\text {band }}$

$0.230 \log \varepsilon=\operatorname{coef}_{\text {band }} \log \varepsilon_{\text {band }}$

Table 4 Proposed new coefficients for the parameter $\Delta$ in spectral bands

\begin{tabular}{ccc}
\hline BAND & Average value $\Delta_{\text {band }}$ & Coef $_{\text {band }(\Delta)}$ \\
\hline UVA & 0.121 & 0.469 \\
PAR & 0.155 & 0.531 \\
\hline
\end{tabular}

Table 5 Proposed new coefficients for the parameter $\varepsilon$ in spectral bands

\begin{tabular}{ccc}
\hline BAND & Average value $\varepsilon_{\text {band }}$ & Coef $_{\text {band( }(\varepsilon)}$ \\
\hline UVA & 2.36 & 0.293 \\
PAR & 5.43 & 0.1575 \\
\hline
\end{tabular}

The correction factor given by Battles' broad band formula is modified for each of the bands as shown in the equations

$$
\begin{aligned}
& C_{B}(U V A)=1.245 \cdot C_{D}+0.469 \cdot \log \Delta+0.293 \cdot \log \varepsilon+0.322 \cdot e^{-1 / \cos \theta} \\
& C_{B}(P A R)=1.245 \cdot C_{D}+0.515 \cdot \log \Delta+0.158 \cdot \log \varepsilon+0.322 \cdot e^{-1 / \cos \theta}
\end{aligned}
$$

To obtain the $\mathrm{C}_{\mathrm{D}}$ factor, which appears in the above equations and thus to correct the geometric effect of the shadow disk on the diffuse irradiance data, we considered the model mentioned in Iqbal (1983) and given by the equation

$$
C_{D}=\frac{1}{\left[1-\frac{S / r^{2}}{2 \pi}\right]}
$$


Where $S$ is the surface of the shadow disk, $r$ the height at which it is placed, $S / r^{2}$ being the solid angle of the portion of sky that it blocks of 0.0913 stereoradians, which represents the ratio 0.014527 of the total vault. The $C_{D}$ factor is hence 1.0147 .

The correction factor $C_{B}$ was calculated according to the expressions (7) and (8) for the bands and their statistical values, as shown in Table 6.

Table $6 \mathrm{C}_{\mathrm{B}}$ correction factor for data sets of both spectral bands

\begin{tabular}{ccc}
\hline $\mathbf{C}_{\mathbf{B}} /$ Band & UVA & PAR \\
\hline Minimum & 1.0004 & 1.0006 \\
Maximum & 1.209 & 1.146 \\
Mean & 1.150 & 1.045 \\
Median & 1.170 & 1.028 \\
\hline
\end{tabular}

\section{Results}

To analyse the deviation of the estimated values of the direct normal irradiance obtained by EM from the experimental values obtained in the measurement campaign, three different error estimators were used: the root mean square error (RMSE), mean bias error (MBE) and mean absolute bias error (MABE). The first represents the Variance of the experimental data versus those obtained by EM, while the last two estimators provide information on over- or under-estimations in a particular range. We also analysed the linear regression between estimated and measured values and we obtained their corresponding $\mathrm{R}^{2}$ coefficients. Figs. 3 and 4 show the correlation between the experimental direct normal irradiance and the values provided by EM.

$$
\begin{aligned}
& R M S E=\left[\frac{1}{N} \sum_{i=1}^{N}\left(E_{i}-O_{i}\right)^{2}\right]^{1 / 2} \\
& M B E=\frac{1}{N} \sum_{i=1}^{N}\left(E_{i}-O_{i}\right) \\
& M A B E=\frac{1}{N} \sum_{i=1}^{N}\left|E_{i}-O_{i}\right|
\end{aligned}
$$

In Table 7 the values of $\operatorname{RMSE}(\%), \operatorname{MBE}(\%)$ and $\operatorname{MABE}(\%)$ are shown, which are the previous estimators calculated in relative terms regarding the average experimental direct normal irradiance in order to emphasize the magnitude of the error. 
Table 7 Statistical results of comparison between direct normal irradiance values provided using the method and the real ones.

\begin{tabular}{cccccc}
\hline Band & $\begin{array}{c}\boldsymbol{I}_{n} \text { (aver.) } \\
\left(W / m^{2}\right)\end{array}$ & $R^{2}$ & $R M S E(\%)$ & $\operatorname{MBE}(\%)$ & $\operatorname{MABE}(\%)$ \\
\hline UVA & 26.18 & 0.934 & 13.50 & -6.38 & 11.07 \\
PAR & 285.76 & 0.866 & 9.73 & 2.21 & 7.25 \\
\hline
\end{tabular}

Where $I_{n}$ (aver.) expresses the average value of the measured direct normal irradiance for each band.

Let us consider that $\mathrm{MBE}(\%)>0$ means that $\mathrm{EM}$ tends to overestimate the true direct normal irradiance values, whereas $\operatorname{MBE}(\%)<0$ corresponds to an underestimation.

According to the values of the $\operatorname{MBE}(\%)$ estimator, the model tends to underestimate the direct normal irradiance of the UVA band by $6 \%$. To better study the deviations, the data set was split into two groups using intervals of the experimental direct normal irradiance below and over the value of $25 \mathrm{~W} / \mathrm{m}^{2}$ in the case of UVA band as can be seen in Table 8 . For values of direct normal irradiance below $25 \mathrm{~W} / \mathrm{m}^{2}$, the model overestimates the direct irradiance by $6 \%$, while for values above below $25 \mathrm{~W} / \mathrm{m}^{2}$ the model underestimates the direct irradiance in a greater proportion. The other two error estimators have similar orders of magnitude if applied to the total data set than if applied to the intervals separately.

Table 8 Statistical results of the comparison broken down into intervals, between direct normal irradiance values provided using the method and the real values.

\begin{tabular}{|c|c|c|c|c|c|}
\hline Band & & $\begin{array}{c}I_{n} \text { (aver.) } \\
\left(W / m^{2}\right)\end{array}$ & $\operatorname{RMSE}(\%)$ & $\operatorname{MBE}(\%)$ & $\operatorname{MABE}(\%)$ \\
\hline \multirow[t]{2}{*}{ UVA } & $\mathrm{I}_{\mathrm{n}} \leq 25 \mathrm{~W} / \mathrm{m}^{2}$ & 15.79 & 15.10 & 6.49 & 11.88 \\
\hline & $\mathrm{I}_{\mathrm{n}} \geq 25 \mathrm{~W} / \mathrm{m}^{2}$ & 32.77 & 12.52 & -10.32 & 12.82 \\
\hline \multirow[t]{2}{*}{ PAR } & $\mathrm{I}_{\mathrm{n}}<280 \mathrm{~W} / \mathrm{m}^{2}$ & 213.83 & 20.83 & 17.01 & 17.16 \\
\hline & $\mathrm{I}_{\mathrm{n}}>280 \mathrm{~W} / \mathrm{m}^{2}$ & 327.37 & 5.32 & 0.08 & 4.16 \\
\hline
\end{tabular}

Regarding the PAR band, and in accordance with the values of the MBE estimator, the model tends to overestimate the direct normal irradiance of the PAR band by $2.2 \%$. To better study the deviations for PAR band, now the data set has been analysed by intervals of experimental direct normal irradiance below and over the value of $280 \mathrm{~W} / \mathrm{m}^{2}$. As shown in table 8 , for values below $280 \mathrm{~W} / \mathrm{m}^{2} \mathrm{EM}$ overestimates the direct irradiance by $17 \%$, while for higher values the direct normal irradiance estimates are good, since the MBE estimator is almost null. The other two error estimators used in this interval measurement, around 5\%, are approximately a quarter of the other interval and a half of the whole PAR band. 


\section{Conclusions and future applications}

In this paper an improved EM method is put forward to determine direct normal irradiance of bands when the available measurements were of global horizontal irradiance. Applying EM two new UVA and PAR band parameterizations were obtained for Valencia in conditions of cloudless skies.

Approximate methods to provide direct irradiance from global have been developed in the literature for broadband measurements, but not for band measurements, and it could then be very helpful to make up for this shortcoming by making through EM determination of direct band irradiance from global horizontal measurements possible, which are more often available.

To validate EM, a campaign of measurements was performed to obtain direct normal irradiance and to compare them with those provided using the method. The results of the comparisons reveal that the accuracy of EM is not great but it is tolerable because it only fails in cases of very low irradiance values, with RMSE(\%) less than $14 \%$ for the two bands analysed.

The proposed model tends to underestimate the direct normal irradiance of the UVA band by $6 \%$, although for values below $25 \mathrm{~W} / \mathrm{m}^{2}$ the model overestimates the direct irradiance by $6 \%$, while for values above $25 \mathrm{~W} / \mathrm{m}^{2}$ the model underestimates it by $10 \%$. The other two error estimators range from $11 \%$ to $15 \%$. The reason for some of these deviations could be due to the negligible presence of very thin clouds in instants considered cloudless by the observer.

Regarding the PAR band, the model overestimates the direct normal irradiance of the PAR band by only 2.2\%. By this, the results of the PAR band are more conclusive, as it has been found that for direct normal irradiance values higher than $280 \mathrm{~W} / \mathrm{m}^{2}$ the MBE error is almost zero and the other two estimator errors are small, about $5 \%$.

Finally an analysis was carried out to adapt the coefficients determined by Battles et al. (1995) to correct the diffuse measurements in case of a shadowband and for broadband to our case of a shadow disk and for our two spectral ranges.

Acknowledgements This work was supported by the Spanish Government through MEC grant MAT200602279, and is a part of the activities of the Grup d'Optoelectrónica i Semiconductors of the Polytechnic University of Valencia. The translation of this paper was funded by the Universidad Politécnica de Valencia, Spain. 


\section{References}

Barth J, Cadet J, Césarini JP, Fitzpatrick TB, McKinlay A, Mutzhas M, Pathak M, Peak M, Sliney D, Urbach F (1999) TC 6-26 report: Standardization of the terms UV-A1, UV-A2 and UV-B, CIE 134-1999 ISBN 3-900-734-94-1.

Batlles F J, Olmo F J, Alados-Arboledas L (1995) On shadowband correction methods for diffuse irradiance measurements. Solar Energy 54(5):105-114.

Drummond AJ (1956) On the measurement of sky radiation. Arch. 602 Meteor. Geophys. Bioklim. B $7: 413-436$.

Gueymard C (1995) SMARTS2: A simple model of the atmospheric radiative transfer of sunshine: Algorithms and performance assessment. FSEC-PF-270-95, Florida Solar Energy Center.

Gueymard C (2003) SMARTS2 code, versión 2.9.2. User’s Manual, Solar Consulting Services Bailey CO. Available from http://rredc.nrel.gov/solar/models/SMARTS/smarts_index.html

Gueymard C (2004) The sun's total and spectral irradiance for solar energy applications and solar radiation models. Solar Energy 76: 423-453.

Häder DP, Lebert M, Marangoni R, Colombetti G (1999) ELDONET-European Light Dosimeter Network hardware and software. J. Photochem. Photobiol. B: Biol. 52:51-58.

Häder DP, Lebert M, Colombetti G, Figueroa F (2001) European light dosimeter network (ELDONET). Helgol Mar Res 55:35-44.

Iqbal M (1983) An introduction to solar radiation. Toronto, Academic Press.

Kudish AI, Evseev EG (2008) The assessment of four different correction models applied to the diffuse radiation measured with a shadow ring using global and normal beam radiation measurements for Beer Sheva, Israel. Solar Energy 82(2):144-156.

LeBaron BA, Michalsky JJ, Perez R (1990) A Simple procedure for correcting shadowband data for all sky conditions. Solar Energy 44:249-256.

Marín Fernández MJ (2007) Estudio de la irradiancia solar ultravioleta y eritemática en la Comunidad Valenciana. Doctoral Thesis University of Valencia (Spain).

Perez R, Ineichen P, Seals R, Michalsky JJ, Stewart R (1990) Modelling daylight availability and 
irradiance components from direct and global irradiance. Sol. Energy 44:271-289.

Pinazo JM, Cañada J, Bosca JV (1995) A new method to determine Ångström's turbidity coefficient: Its application for Valencia. Solar Energy 54:219-26.

Serrano MA, Boscá JV and Cañada J (2008) The determination of a band factor to express irradiance of UV and PAR wavelength ranges in a clean and dry atmosphere at Valencia (Spain). International Journal of Ambient Energy 29 (4):171-180.

Utrillas MP, Boscà JV, Martinez-Lozano JA, Cañada J, Tena F, Pinazo JM (1998) A comparative study of Spectral2, and Smarts2 parameterised models based on spectral irradiance measurements at Valencia, Spain. Solar Energy 63:161-171.

Utrillas MP, Marín MJ, Esteve AR, Tena F, Cañada J, Estellés V, Martínez Lozano JA (2007) Diffuse UV erythemal radiation experimental values. Journal of geophy. Research 112:387-395. 


\section{FIGURE CAPTIONS}

Fig. 1 Parameterization of the $\mathrm{I}_{\mathrm{n}} / \mathrm{I}$ fraction of the UVA band versus $\mathrm{m}_{\mathrm{r}}$ in cloudless conditions in Valencia, Spain

Fig. 2 Parameterization of the $I_{n} / I$ fraction of the PAR band versus $m_{r}$ in cloudless conditions in Valencia, Spain

Fig. 3 Comparison between direct normal irradiance provided by the method and the real direct normal irradiance of the UVA band in Valencia, Spain

Fig. 4 Comparison between direct normal irradiance provided by the method and the real direct normal irradiance of the PAR band in Valencia, Spain

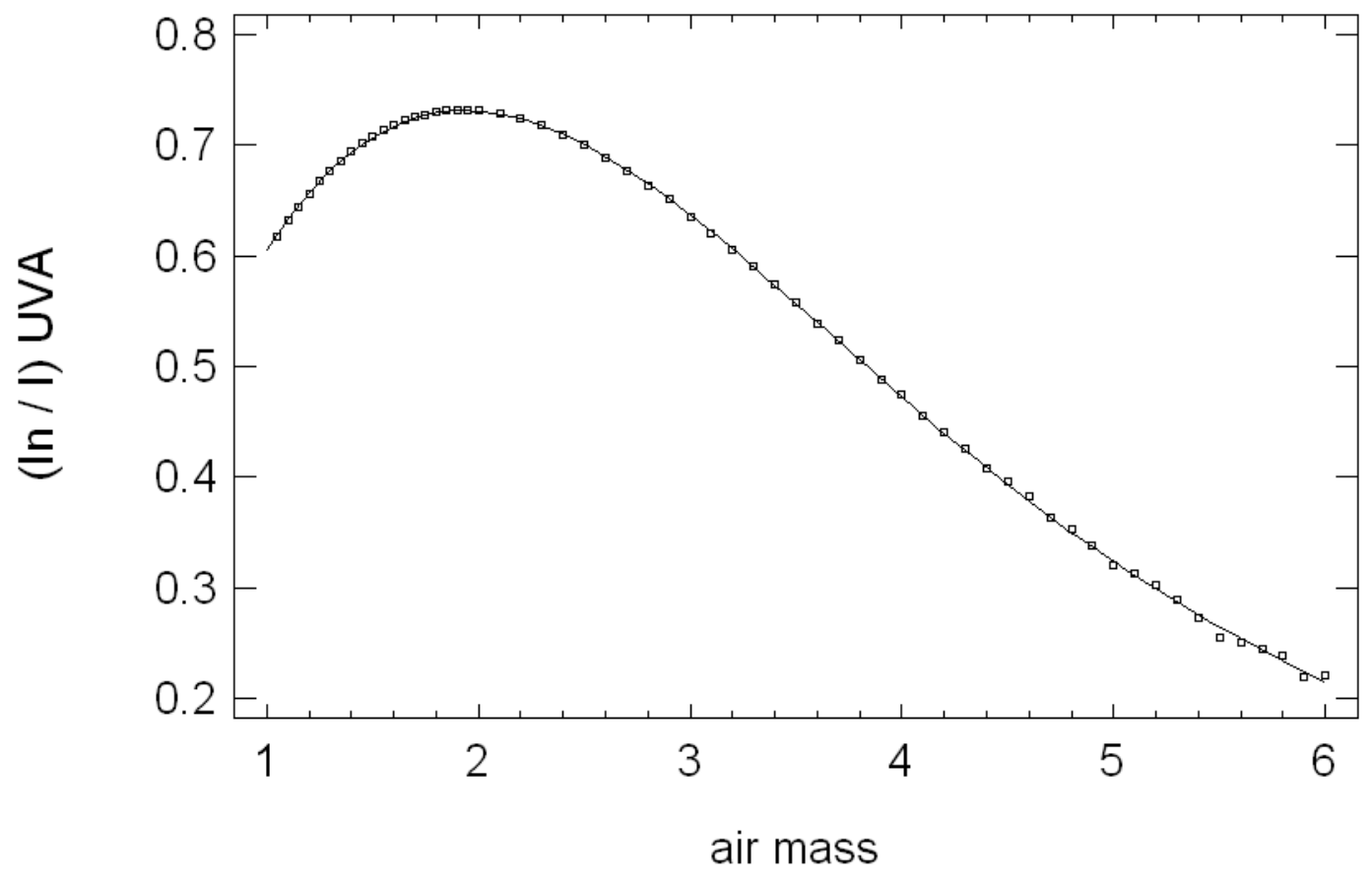




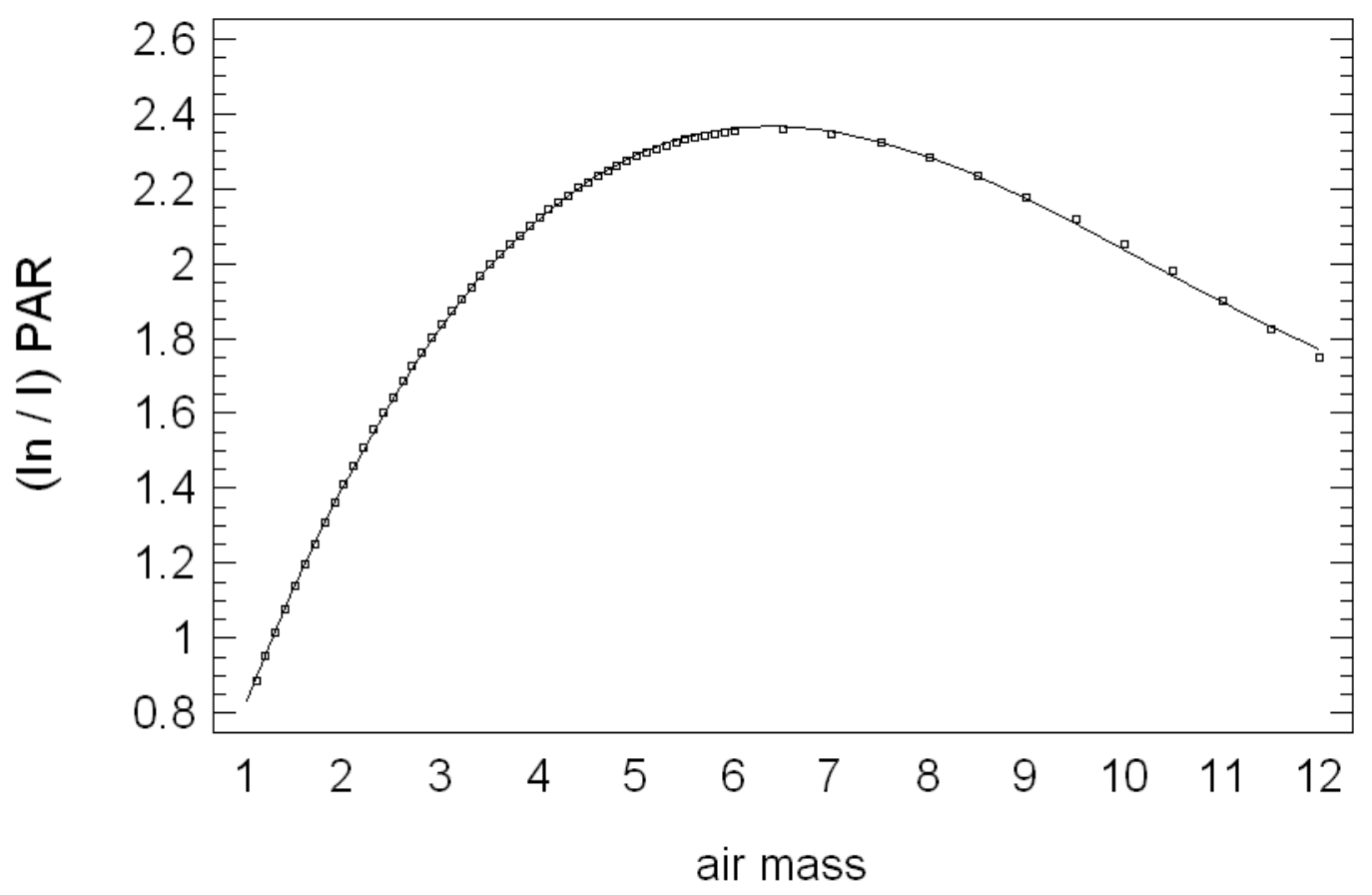




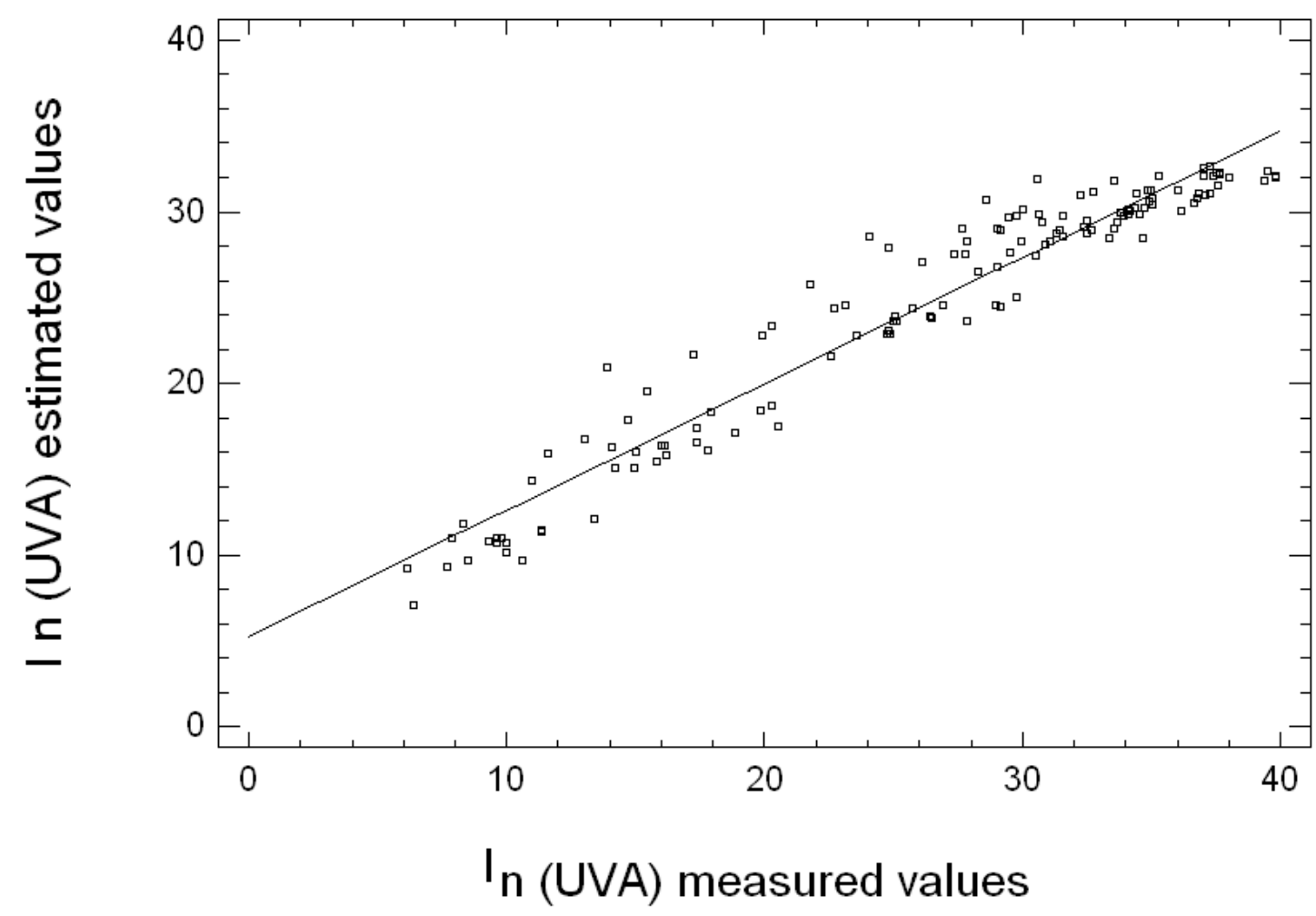




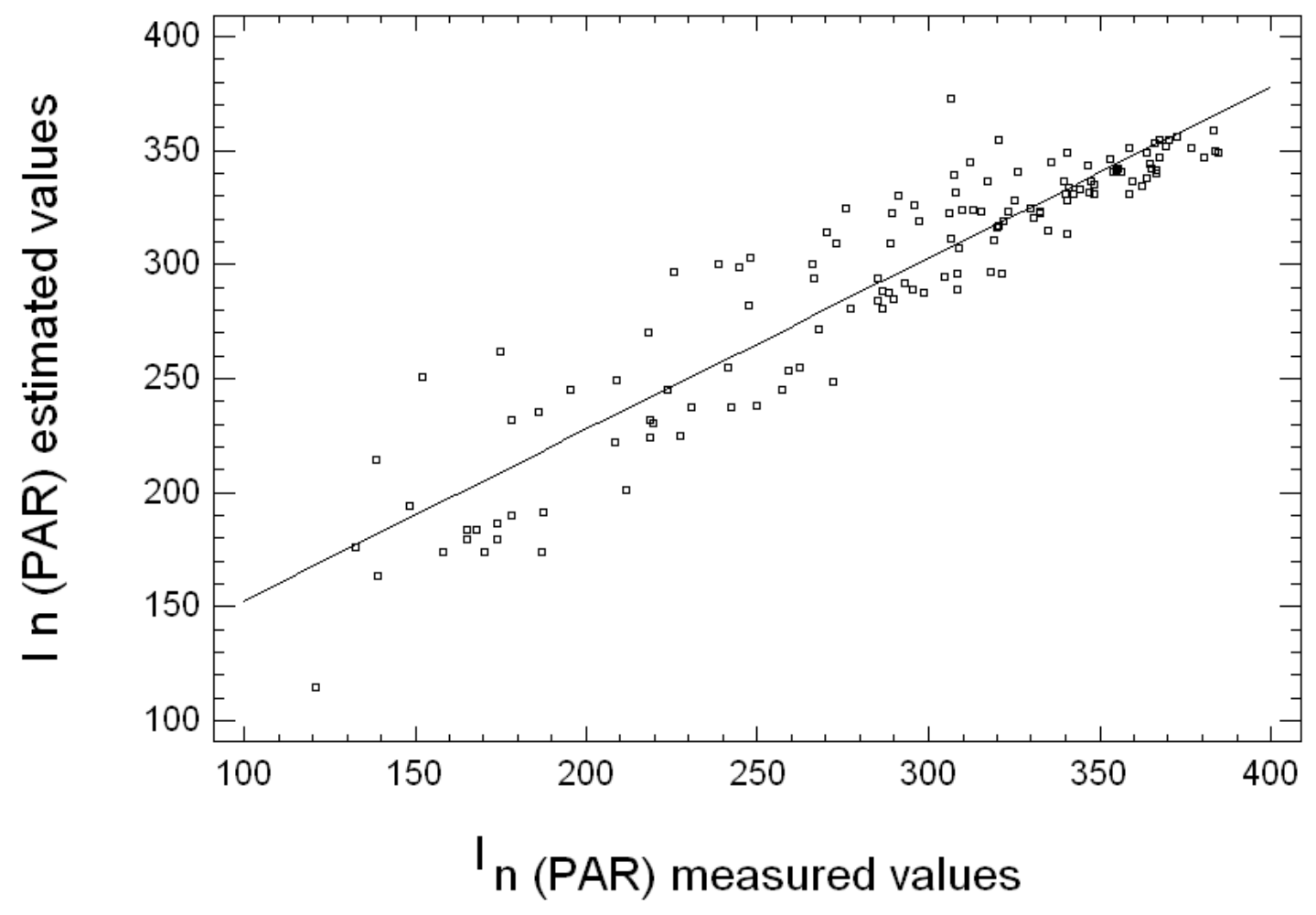

